\title{
THE ASSOCIATION OF SIRENOMELIA WITH POTTER'S SYNDROME
}

\author{
BY
}

\author{
J. G. BEARN
}

From the Department of Anatomy, Middlesex Hospital, London

(RECEIVED FOR PUBLICATION FEBRUARY 15, 1960)

The Greeks considered congenital deformities to be of divine origin and eventually these monsters were thought to indicate a divine warning of some future calamity and the infant and even the mother were sacrificed to propitiate the gods (Glenister, 1957). The sympodial deformity has been recognized from earliest times and may well have given

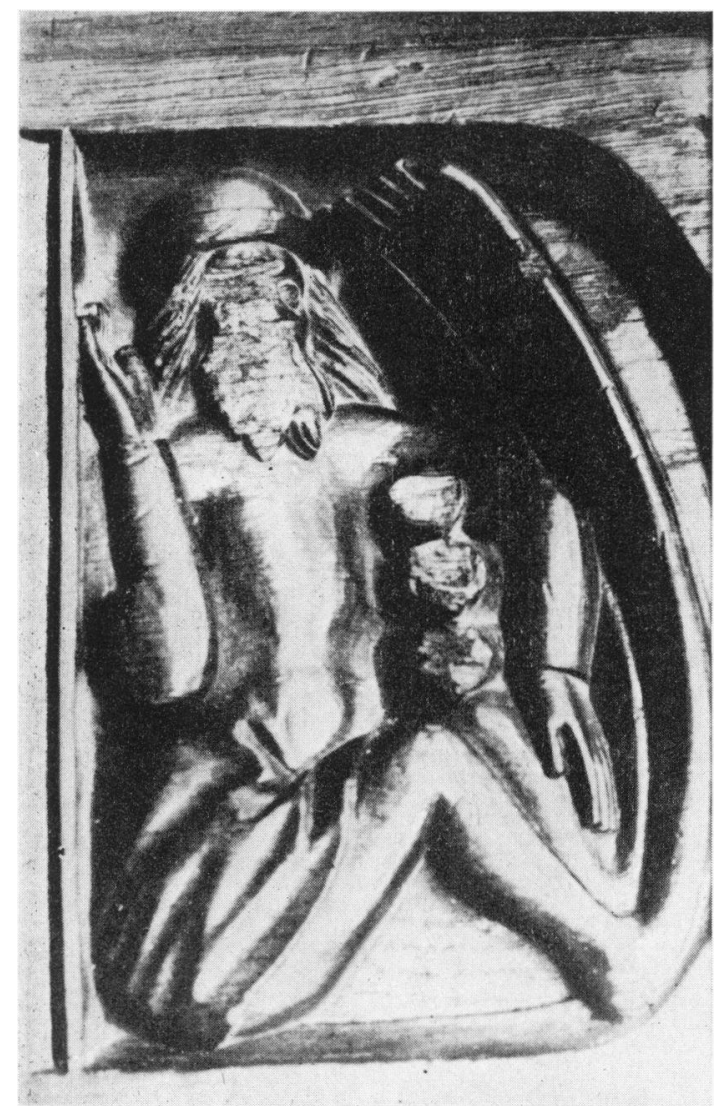

Fig. 1.-The sciapod or shadow foot. This carving from a fourteenth century bench end in the nave of Dennington Church, Suffolk, shows a fused lower limb and a large foot with 10 toes. Unlike the true sympodial limb, the knees flex posteriorly. rise to the myth of the siren. The legendary monster of the Lybian desert, the sciapod, or shadow foot, described by both Herodotus and Pliny (Fig. 1), may well have had a similar origin. This man used his foot as a sunshade when resting. Early writers showed a remarkable degree of wishful thinking and poetic licence in their descriptions of

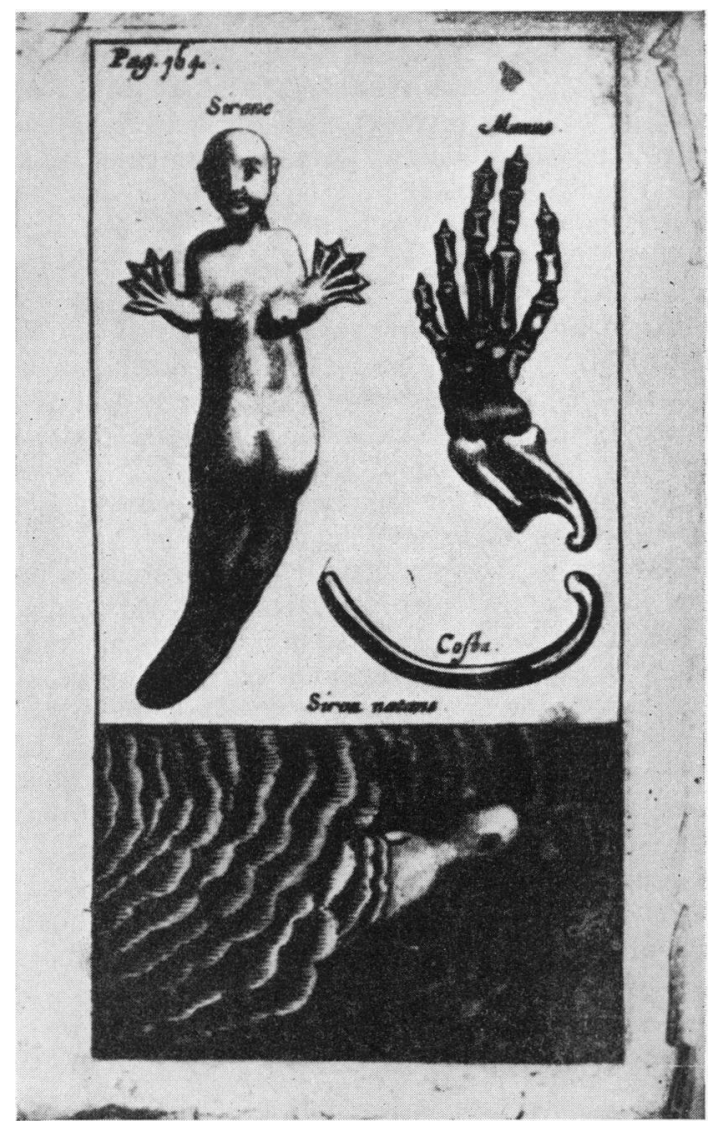

Fig. 2.-The sympodial foetus described and illustrated by Thomas Bartholin. Note the presence of mammary glands and webbed hands. 
the sympodial monster. Bartholin (1654) even reported mammary glands and webbed fingers in his case (Fig. 2).

Although the sympodial deformity is a rare condition a number of cases have been reported in the literature, and the subject has been reviewed by Kampmeier (1927) and Hendry and Kohler (1956).

The case described in this report shows the association of the abnormality with the syndrome described by Potter (1946) of renal agenesis, hypoplasia of the lungs and a typical facies. This association does not seem to have been reported in any of the cases of sympodia described up to the present, although it is probable that the association is common.

The anatomical and embryological aspects of this case have been described elsewhere (Bearn, 1960).

\section{Case Record}

A sympodial foetus, stillborn, and fixed in formalin, was made available for study.

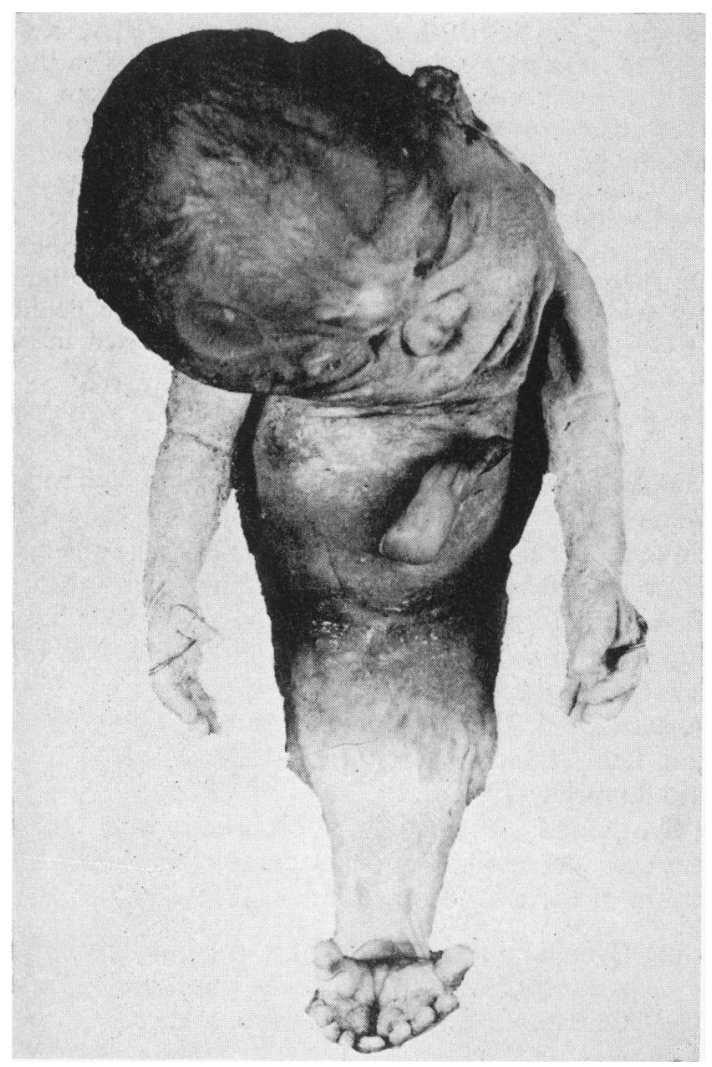

Fig. 3.-The sympodial foetus showing the fused lower limb, with 10 toes, the two little toes fused and big toes on outer sides of foot.

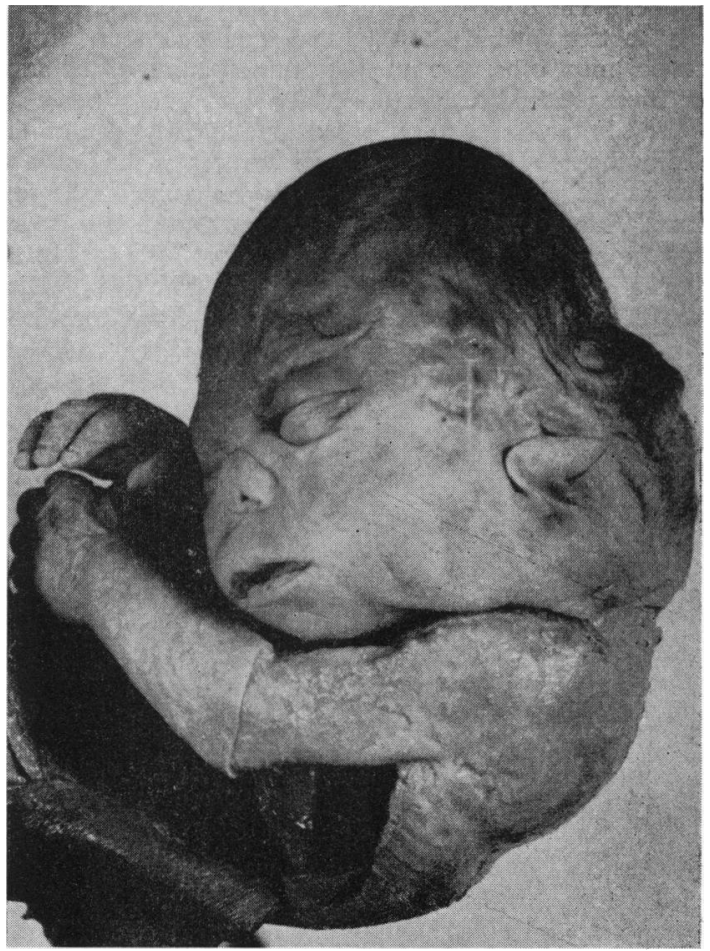

Fig. 4.-The face of the sympodial foetus showing the features typical of Potter's syndrome.

Obstetric History. The mother was married, aged 22 years and had given birth two years previously to a normal 40 week infant, which had died before the arrival of the midwife. During the second pregnancy, there was no history of any abnormality and no history of oligohydramnios was reported. Labour was at 40 weeks and was uneventful, lasting six hours. She was group $O$, Rhesus positive. After the birth of the abnormal child, the blood of both the mother and father was again checked, and no ABO or other incompatibility was found.

External Examination. The specimen (Fig. 3) was a human foetus of indeterminate sex, with a 2 nd degree sympodial deformity, weighing $2 \mathrm{lb}$. $1 \mathrm{loz}$.

The face (Fig. 4) showed all the features first described by Potter (1946) in association with bilateral renal agenesis: flattening of the nose, recession of the chin, soft flat ears, with apparent absence of the cartilage, and low positioning of the ears on the side of the head. The eyes showed a wide intra-ocular distance, and prominent epicanthic folds, forming a wide semicircle on each side of the nose and covering each medial palpebral commissure.

The upper limbs and thorax were normal. The pelvis was reduced in size and no external genitalia could be 
found. There was a blind pit dorsally at the lower end of the trunk which could have represented an imperforate anus, otherwise no sign of an opening of the anus or urethra could be found.

The lower limbs were joined together, the site of the fusion being along the post-axial borders of the limbs as far as the tips of the little toes. The soles of the feet faced anteriorly. Ten toes were present, the two outermost toes being the big toes, and the two little toes being partially fused together in the midline. The two patellae were felt on the postero-lateral aspect of the knee, and the joint could be flexed anteriorly.

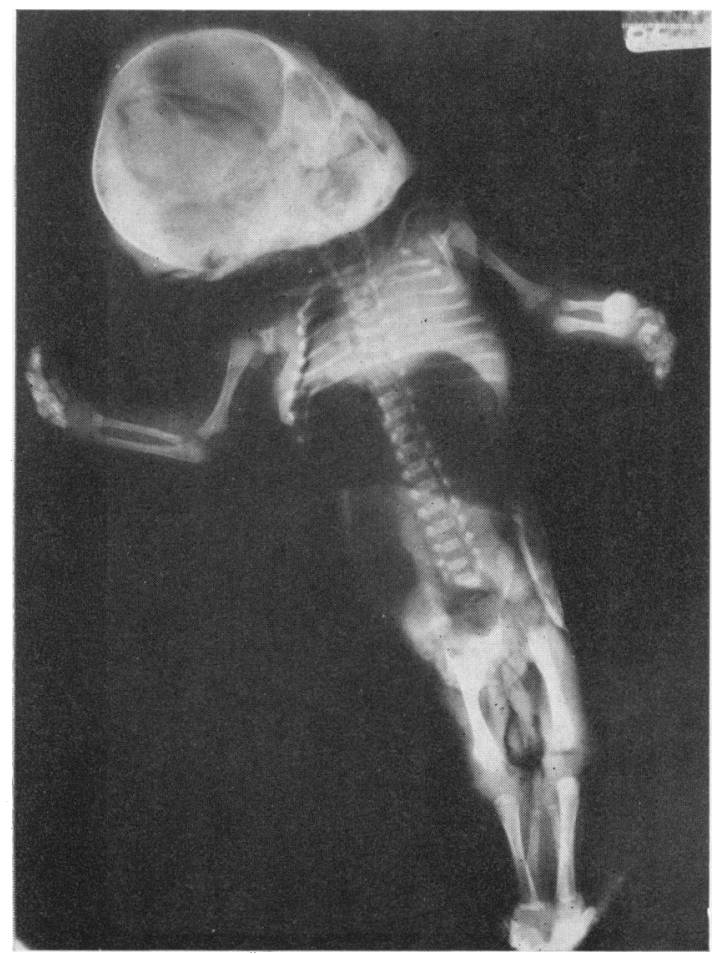

Fig. 5.-Radiograph showing the double skeleton of the single limb, with the fibulae lying internal to the tibiae.

Radiological Examination of the Lower Limb. The radiograph showed no abnormalities in the upper limbs, head and trunk (Fig. 5). Six lumbar vertebrae and the first two pieces of the sacrum were present, the remaining three pieces and the coccyx being absent. The ilium was present on each side, and the pubis was represented by a fused midline bone. The radiograph of the fused limb showed the presence of both femora, and both tibae and fibulae, their relative positions being reversed. Two tarsal bones, and the metacarpals and phalanges, were present.

Internal Examination. The internal structures of the head and neck were normal. The heart was normal, but the lungs were markedly underdeveloped and failed to fill the thoracic cavity, this hypoplasia being more marked on the left side, and the pleural cavities were filled with fluid. The size of the thoracic cavity was normal. The alimentary tract was normal as far as the rectum, which ended as a blind stump. The liver, spleen and pancreas were normal, the left adrenal only was present, and was flattened antero-posteriorly and the kidneys and ureters were absent except for a small mass on the left side below the adrenal gland, which was shown histologically to contain some renal tissue. The pelvic cavity was very shallow and contained none of its normal contents. The urogenital tract was absent and the external genitalia could not be found. The testes were present in each iliac fossa. Only the right umbilical artery was found.

The Skeleton and Musculature of the Pelvis and Lower Limb. The main muscle groups of the pelvis and the fused limb were all present and with very few exceptions, even the individual muscles of each group could be identified. The muscles of the gluteal region were present and were in their normal positions, the greater trochanters being in a more posterior position than usual. These two regions were in much the same relative positions as in the normal foetus. The upper two-thirds of the thigh showed only a partial reversal from the normal position, and each patella was identified on the postero-lateral aspect of the thigh. From the knee joints downwards, the limbs showed a complete reversal of position, and flexion of the knee joint was in an anterior direction. The tibia and fibula on each side were reversed, the two fibulae being adjacent to each other on the internal aspects of the tibiae. The femoral, obturator and sciatic nerves were identified in each limb supplying their respective muscle groups. The details of the muscles and skeleton have been reported in an earlier paper (Bearn, 1960).

\section{Discussion}

The condition of sympodial foetus is most uncommon. Ballantyne (1898) collected only 120 cases in the literature; Kampmeier (1927) collected 51 more cases, including one of his own. Since then occasional reports of individual cases have appeared in the literature: Dreyfuss (1928), Newbill (1941), Resnick (1945), Dodek and Friedman (1950), Potter (1952), Foulkes and McMurray (1954), Jones and Lee (1955), Hendry and Kohler (1956), Jolly and Lamont (1958).

Sympodial foetuses are classified into three degrees, depending on the completeness of the fusion of the two limbs, Förster $(1861,1865)$.

(1) Symelia apus. No feet are present, the limbs are completely fused into one single limb. One femur and one tibia are present.

(2) Symelia unipus. One foot is present, this being a partial fusion of the two feet. Up to 
ten toes may be found, the little toes being fused together and the plantar surface of the foot facing anteriorly. Two femora and two tibiae and fibulae are present, the latter bone being medial to each tibia. The main muscle groups can usually be identified.

(3) Symelia bipus. Two feet are present, giving the appearance of fins-hence the name 'mermaid' foetuses for this abnormality. The fusion of the limbs extends only as far as the ankles, and the muscles of the two limbs are all present.

The position of the fused limb in this condition is of great embryological interest, as it demonstrates a persistence of the early foetal unrotated position of the limb. The normal lower limb undergoes internal rotation, so that the post-axial border and digit of the little toe become lateral and the ventral surface faces posteriorly. In the sympodial deformity the developing limb buds are fused from the start along their post-axial borders and rotation is therefore impossible.

Causation of the Sympodial Deformity. This has been discussed in detail elsewhere (Bearn, 1960). Bolk (1899) and Ballantyne (1904) both suggested that the defect was primarily a failure of development of the caudal segments at a very early stage before the limb buds form. Wolff (1936) has produced the sympodial deformity in the chick by destroying the caudal end of the early embryo with x-rays. This work of Wolff (1936) confirms experimentally the suggestions that the primary defect in the sympodial deformity is one of the caudal region of the embryo, but how this defect is produced in the early human embryo is not known. The defect must also involve the presumptive area for the urogenital tract, as these structures including the kidney do not develop in the human monster.

The Association of Sympodia with Potter's Syndrome. The face of this foetus (Fig. 4) shows all the characteristics, first described by Potter (1946), found in cases of renal agenesis. 'The most striking feature consists of an increase in width between the eyes and the presence of an unusually prominent fold arising at the inner canthus of each eye. The fold sweeps downward and laterally to form a wide semicircle under the inferior medial aspect of each orbital space. Other changes . . . are a flattening and slight broadening of the nose, an unusually receding chin and large low-set ears which have proportionately little cartilage.' Although this facies has not been reported in any of the papers on sympodia published since Potter's paper in 1946, it is likely that most sympodial foetuses show these features, in view of the usual absence of renal tissue in this deformity. In the paper by Hendry and Kohler (1956) Fig. 6 shows some of the features of this facies, and in the paper by Jolly and Lamont (1958) Fig. 1 shows most of the characteristics, including the epicanthic fold. However, the specimen described by Jones and Lee (1955), now preserved in the Anatomy Department of the Middlesex Hospital Medical School, shows a normal facies in spite of complete absence of renal tissue. Hilson (1957) has shown that abnormalities of the ears, somewhat similar to those seen in Potter's syndrome, occur in other malformations of the urinary tract, such as bifid ureter, or absence of one kidney.

It is not yet possible to explain the association of the typical facies described by Potter (1946) occurring in renal agenesis and in cases of sympodia.

It is possible that the peculiar facies may be explained by the compression of the head by the uterine wall, secondary to the oligohydramnios which is usually present both in sympodia and in cases of renal agenesis without gross abnormalities of the lower limbs.

The flattening of the nose, the receding chin and the flattened malpositioned ears could all be due to a mechanical pressure effect on the developing head.

The presence of oligohydramnios was not reported in the obstetric history of this patient, although it is often noticed in both sympodia and renal agenesis, and it is probable that there is a direct relation between the renal agenesis and the oligohydramnios. Browne (1955) believes that oligohydramnios with compression of the foetus is a factor in the development of club foot deformity. For example, Davidson and Ross (1954) described six cases of Potter's syndrome, all of which had club foot. Although mechanical pressure of the uterus may well explain the club foot deformity associated with renal agenesis and oligohydramnios, there are no grounds for believing that the gross deformity of sympodia could be a consequence of these conditions.

Potter (1946) also described for the first time the hypoplasia of the lungs which occurs in renal agenesis. This foetus showed the hypoplasia to a marked degree, the left lung filling only a fraction of the cavity. Again, recent reports on sympodia do not discuss this point, although Jolly and Lamont remark that the lungs in their case 'were poorly expanded'. It is again likely that the examination of most cases of sympodia with this point in view would reveal the abnormality. It is not possible to explain the failure of development of the lungs on 
mechanical grounds, as the thoracic cavity was normal in size. The reason for the hypoplasia remains obscure.

The absence of the kidneys explains the large flattened appearance of the adrenal gland found in this case and reported in most cases of sympodia, and also by Potter (1946) in her cases of renal agenesis. The development of the kidneys presumably moulds the adrenals into their characteristic shape in the normal foetus.

The observation that all sympodial monsters have but one umbilical artery is a curious finding. In this case it was the right umbilical artery which persisted, although both Ballantyne (1904) and Kampmeier (1927) found, in their cases, that the artery within the umbilical cord was a persistent vitelline artery.

The sex of this foetus is male, and all collected series show a predominance of this sex. Kampmeier (1927) found 38 males out of a series of 52 sympodial monsters, and Potter (1952), in her series of renal agenesis, found a majority of males, only four out of 26 being female.

\section{Summary}

A case of sympodia is described, showing a second degree deformity (Symelia unipus).

The association of this deformity with Potter's syndrome, the typical facies, aplasia of the lungs and renal agenesis, is described.

I am indebted to Professor E. W. Walls for help in the preparation of this paper, to Dr. I. Mackenzie for making this foetus available for study, Mr. P. R. Runnicles for taking the photographs and to Dr. M. E. Carruthers for help with the dissection of the foetus.

\section{REFERENCES}

Bain, A. D. and Scott, J. S. (1960). Renal Agenesis and severe urinary tract dysplasia. Brit. med. J., 1, 841 .

Ballantyne, J. W. (1898). The occurrence of a non-allantoic or vitelline placenta in the human subject. Trans. Edinb. obstet. Soc., 23, 54.

- (1904). Manual of Antenatal Pathology and Hygiene, Vol. 2: The Embryo. Green, Edinburgh.

Bartholin, T. (1654). Historiarum anatomicarum rariorum centuria II. Historia XI. Hafniae, Copenhagen.

Historia XI. Hafniae, Copenhagen.
Bearn, J. G. (1960). The sympodial foetus, with a consideration of the causation. Anat. Rec., 136, 107.

Bolk, L. (1899). De Sympodie, een voorbeeld van pathologische segmentaal-anatomie. (ieneesk. Bl., 4, 301. (Quoted by Kampmeier.)

Browne, D. (1955). Congenital deformities of mechanical origin. Arch. Dis. Childh., 30, 37.

Davidson, W. M. and Ross, G. I. M. (1954). Bilateral absence of the kidneys and related congenital anomalies. J. Path. Bact., 68, 459.

Dodek, S. M. and Friedman, J. M. (1950). A sirenomelian monster. J. int. Coll. Surg., 14, 226.

Dreyfuss, M. (1928). A case of sympus dipus. Amer. J. Obstet. Gynec., 15, 52.

Förster, A. (1861, 1865). Die Missbildungen des Menschen, nebst einem Atlas. Friedrich Manke, Jena.

Foulkes, J. F. and McMurray, J. (1954). A case of sympodia. J. Obstet. Gynaec. Brit. Emp., 61, 827.

J. Obstet. Gynaec. Brit. Emp., 61, 827.
Glenister, T. W. (1957). Some history and lore relating to teratogenesis. Charing Cross Hosp. Gaz., 55, 105.

Hendry, D. W. and Kohler, H. G. (1956). Sirenomelia (“Mermaid”). J. Obstet. Gynaec. Brit. Emp., 63, 865.

Hilson, D. (1957). Malformation of ears as sign of malformation of genito-urinary tract. Brit. med. J., 2, 785 .

Jolly, H. and Lamont, Edith M. (1958). Sirenomelia: Sympus dipus ("Mermaid"). Arch. Dis. Childh., 33, 226.

Jones, R. L. and Lee, I. N. (1955). A case of symeliac foetus. Arch. Middlesex Hosp., n.s. 5, 188.

Kampmeier, O. F. (1927). On sireniform monsters, with a consideration of the causation and the predominance of the male sex among them. Anat. Rec., 34, 365 .

Newbill, H. P. (1941). Sirenomelian monster (sympus). An anatomic presentation. Amer. J. Dis. Child., 62, 1233.

Potter, E. L. (1946). Facial characteristics of infants with bilateral renal agenesis. Amer. J. Obstet. Gynec., 51, 885. Year Book Publishers, Chicago.

Resnick, L. (1945). A case of sympus dipus. J. Obstet. Gynaec. Brit. Emp., 52, 515.

Wolff, E. (1936). Les bases de la tératogénèse expérimentale des vertébrés amniotes, d'après les résultats de méthodes directes. Arch. Anat. (Strasbourg), 22, 1.

\section{Addendum}

Since this paper was prepared Bain and Scott (1960) have published a series of 50 cases with renal agenesis and other forms of severe urinary tract dysplasia. They report that seven of these had gross defects involving the caudal end of the foetus such as spina bifida or sirenomelia. 